Ann. Parasitol. Hum. Comp., 1992, $67: \mathrm{n}^{\circ} 5,155-160$.

Mémoire.
Key-words: Spatial distribution. Temporal distribution. Prevalence. Cestodes. Taenia taeniaeformis. Taenia mustelae. Cladotaenia sp.

Mots-clés : Distribution spatiale. Distribution temporelle. Prévalence. Cestodes. Taenia taeniaeformis. Taenia mustelae. Cladotaenia sp.

\title{
SPATIOTEMPORAL DISTRIBUTION OF FOUR SPECIES OF CESTODES IN A LANDSCAPE OF MID-ALTITUDE MOUNTAINS (JURA, FRANCE)
}

\author{
M. H. LE PeSTeUR, P. GiRAudouX, P. DElatTRe, J. P. DAMANGe, J. P. QUÉRÉ
}

\section{SUMMARY}

In eastern France (Jura mountains), from 1985 to 1986 the prevalences of Taenia taeniaeformis, Taenia mustelae, Cladotaenia sp., were studied in rodents from an area of about 1,000 ha. Gradients of prevalence were observed according to habitats and time. Open habitat/close habitat gradients were observed, decreasing for Taenia taeniaeformis, increasing for Taenia mustelae and Clado- taenia sp. The prevalence of cestodes varied according to time, at the interannual level for Taenia mustelae, and at the seasonal level for Taenia mustelae and Cladotaenia sp., the spring and summer phase of the cycle being critical for the transmission. Results are compared with those obtained on Echinococcus multilocularis, in the same study area.

RÉSUMÉ : Distribution spatiotemporelle de quatre espèces de cestodes dans un paysage de montagne de moyenne altitude (Jura, France).

L'infestation des rongeurs par Taenia taeniaeformis, Taenia mustelae, et Cladotaenia sp., a été étudiée dans les régions montagneuses de l'est de la France (Jura) à l'échelle d'un site d'environ 1000 ha. Des gradients d'infestation ont été observés, fonction de l'espace et du temps. Ces gradients s'établissent des milieux ouverts vers les milieux fermés; dans un sens croissant pour Taenia mustelae et Cladotaenia sp., décroissant pour Taenia taeniaeformis.
En fonction du temps, l'infestation des rongeurs varie; d'une année à l'autre pour Taenia mustelae, d'une saison à la suivante pour Taenia taeniaeformis et Cladotaenia sp., les périodes printanières et estivales étant les plus critiques pour la transmission. Les résultats sont comparés à ceux obtenus précédemment pour Echinococcus multilocularis sur le même site.

\section{INTRODUCTION}

"The definition of populations is fundamentally neither spatial nor related to time. Nevertheless, the first descriptive characteristics of populations are spatial and related to time » (Legay and Debouzie, 1985).

Studies of species in a heterogeneous habitat must take both these characteristics of populations into account. The scale of the landscape represents one level of heterogeneity. This level offers good opportunities for research in parasite ecology. Such studies are generally carried out as a part of medical or veterinary public health programmes. They are based on stratified sampling of the habitat of parasitized hosts (Rioux et al., 1981) and lead to defining cartography of habitats with high risks of infestation (Dedet, 1977).

The development of control methods against zoonotic parasites such as Echinococcus multilocularis Leuckart, 1856, is dependent on an understanding of their life cycles and transmission dynamics in each predator-prey rela-

Laboratoire d'Écoéthologie, Université de Montpellier II, ISEM, F 34095 Montpellier Cedex 05.

Accepté le : 22 mai 1992. tionship. These have been studied in four species of larval cestodes of rodents, namely Taenia taeniaeformis Batsch, 1786, Taenia mustelae Gmelin, 1790, Cladotaenia circi Yamaguti, 1935, and Cladotaenia globifera Batsch, 1786. An important aim was to compare their dynamics with those previously reported for E. multilocularis (Delattre et al., 1985, 1988, 1990; Le Pesteur, 1990). Because the movements of definitive hosts (Canidae, Felidae, Mustelidae and Birds of preys) can be extensive, the prevalence data of cestodes in them provides only limited information on focality. As the movements of rodents are generally limited to no more than about one hectare, we have studied the larval phase of these cestodes in them and compared their prevalence between habitats and between seasons. The results are reported in this paper.

\section{MATERIAL AND METHODS}

\section{STUDY AREA}

The material was collected from an area of about 1,000 ha in the district of Levier ( $850 \mathrm{~m}$ of latitude - Jura, France) near the village of Septfontaine, during two years: 1985-1986. The landscape matrix is permanent grassland (meadows and pastures), divided 


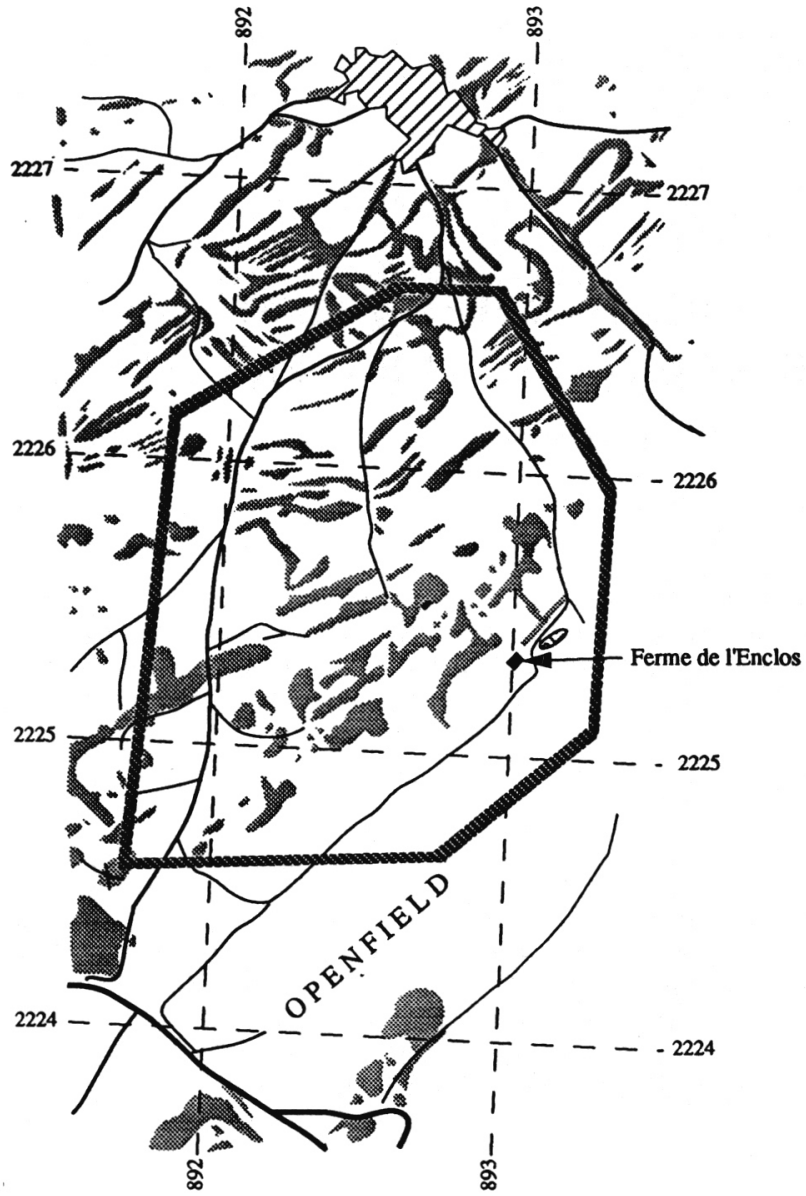

Hedges $\quad-\quad-2225 \begin{aligned} & \text { Lambert coordinates } \\ & \text { (mesh is } 1 \mathrm{~km})\end{aligned}$

Grassland Study area limit

Septfontaines village

Fig. 1. - Map of the study area.

by a hedgerow network, that we'll name « bocage » (Goulty, 1991) (Fig. 1).

Six types of habitat were used to describe the elements of the landscape. These were 1) meadows (68\% of the study area); 2) pastures, grazed by cattle, with their number decreasing from the village to the openfield $(17 \%) ; 3$ ) ploughed fields, representing a very low percentage of the study area (less than $1 \%$ ); 4) fields borders; 5) edges, these were diverse, especially those between two open habitats, such as meadow/ploughed field, border of a road in a field, meadow/pasture, etc. $(6 \%) ; 6)$ hedgerows and groves, where deciduous trees were dominant $(8 \%)$.

\section{TRAPPING}

Sampling was carried out four times each year (April, June, August and October). Rodents were captured with INRA trap lines (Spitz et al., 1974). Each line, about $100 \mathrm{~m}$ length, involved 34 traps with a regular interval of $3 \mathrm{~m}$ between each. From April 1985

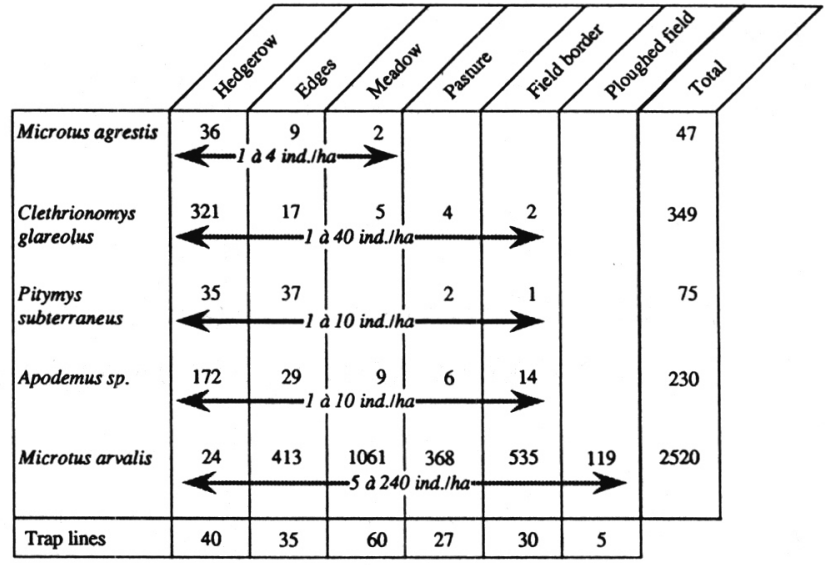

FIG. 2. - Number of captures and number of trap lines. Estimations of densities are obtained from the number of capture per line multiplied by correcting factors (Spitz et al., 1974).

to October 1986, 19,700 m of trap lines were laid. During each sampling period of 3 days, about 25 lines were set up, and traps were patroled every day, so that the sampling pressure is 2,550 trapping days, at less. Each type of habitat was sampled according to its importance in area (Fig. 2). For each season, trap lines were at the same place, but were changed from one season to another, in order to avoid overtrapping. Captures allowed us to establish an abundance index as a mean number of captures per line and per habitat. These indexes can be transformed into densities using correcting factors established by Spitz et al. (1974).

Intensive trapping was performed 3 times on quadrats including hedges or groves in order to catch almost all accessible rodents. A total of 939 traps were laid $(330,420,189)$. Those data will be used separately, in chapter "Prevalence/Habitat relationships" only.

INRA traps are suitable for catching small species of rodents weighing less than $50 \mathrm{~g}$. Hence, only a few young of $A$. terrestris were captured, and this did not allow us to estimate the prevalence of cestodes in this species.

The relative age of the rodents was established by weighing the dry crystalline lens (Martinet, 1966; Le Louarn, 1971; Bourlière and Spitz, 1975).

Rodents were dissected and their liver examined for cysts macroscopically. Both species of Cladotaenia were pooled because of difficulties in differentiating the one from the other. Generally, this method did not permit diagnosis of the very early stages of infestation. In this study, the rodents which were old enough to have macroscopically detectable cysts were called " detectable parasite rodents ". For each species of rodent and cestode, the « detectable parasite rodents " category was defined from the minimal weight of the crystalline lens below which no infested rodent could be observed (Delattre et al., 1985).

\section{RESULTS}

\section{RODENT POPULATION KINETICS}

Six species of rodents were captured: 2,520 Microtus arvalis, 349 Clethrionomys glareolus, 230 Apodemus sp., 24 Arvicola terrestris, 75 Pitymys subterraneus, 47 Microtus agrestis. The general rough spatial distribution of the main 
species are illustrated in Figure 2. Populations showed seasonal and inter annual variations of abundance. In our study (1985-1986) the variations in the number of each population were synchronous and the level of abundance of rodents was high. Specific seasonal variations were noted (low spring lebel/high autumn level). Average densities of 1986 were half those of 1985 .

Analysis of variance of crystalline lens weights showed that the mean age of populations did not vary significally and greatly according to habitats, and did not vary from one year to another. In spring, populations showed a high proportion of old animals which had survived the winter. From spring, populations progressively got younger until the autumn, when nearly the whole population was composed of animals born during the year (Fig. 6).

\section{HOST-PARASITE RELATIONSHIPS}

The number of rodents with detectable cysts, age structures and species of cestode are correlated in Figures 3 and 4. Cladotaenia sp. infested mainly C. glareolus and Apodemus sp., rodents of close habitats. T. taeniaeformis mainly parasitized $P$. subterraneus, $M$. agrestis and $M$. arvalis, rodents of open habitats and borders. The prevalence of $T$. mustelae was high for $C$. glareolus, $P$. subterraneus and M. agrestis, $i$. e. rodents of close habitats and borders.

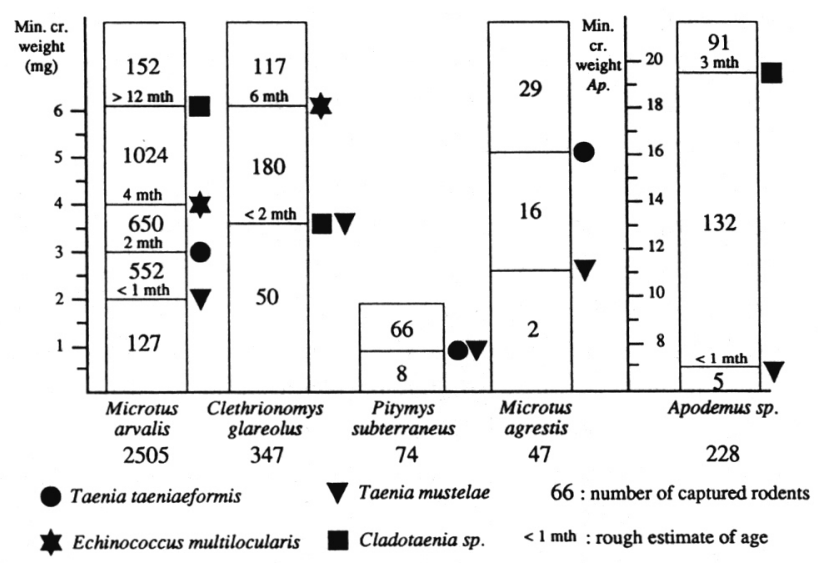

FIG. 3. - Minimum crystalline lens weights (mg) of the infested rodents according to the different species of cestodes (rodents whose crystalline lens weight is over the limit are considered as « detectable parasite rodents »).

\section{PreValenCE/Habitat Relationships}

Taenia taeniaeformis showed increasing prevalences from close habitats to open habitats, whereas $T$. mustelae showed a reverse gradient (fig. 5).

Cladotaenia sp. needed close habitats as 38 of the 39 cases were recorded in these habitats. Half of the captures of
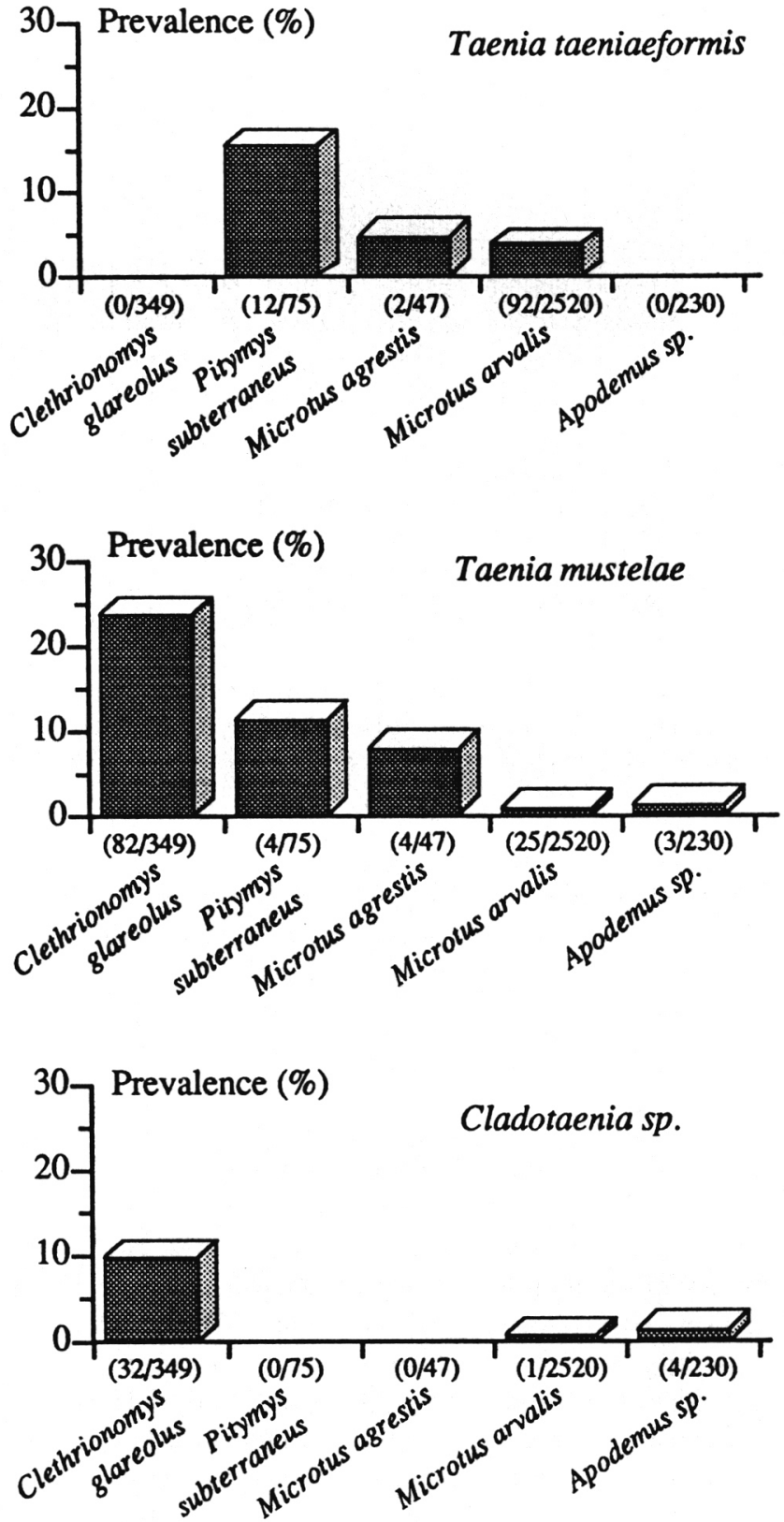

Fig. 4 - Prevalence of different species of cestodes in their intermediate hosts $(=$ number of infested rodents/total number of rodents).

infested rodents were concentrated in two trap lines only. One was located in a grove of deciduous trees, north-east of the "Ferme de l'Enclos", and the other in a hedge near a highway suggesting a clustered distribution of this cestode.

Using intensive trapping within quadrats including close habitats, it was possible to determine the distribution of $T$. mustelae locally in $C$. glareolus. The prevalence in close habitats (non-significant differences between deciduous trees/coniferous trees) was $11.2 \%(16 / 143)$, in the bor- 


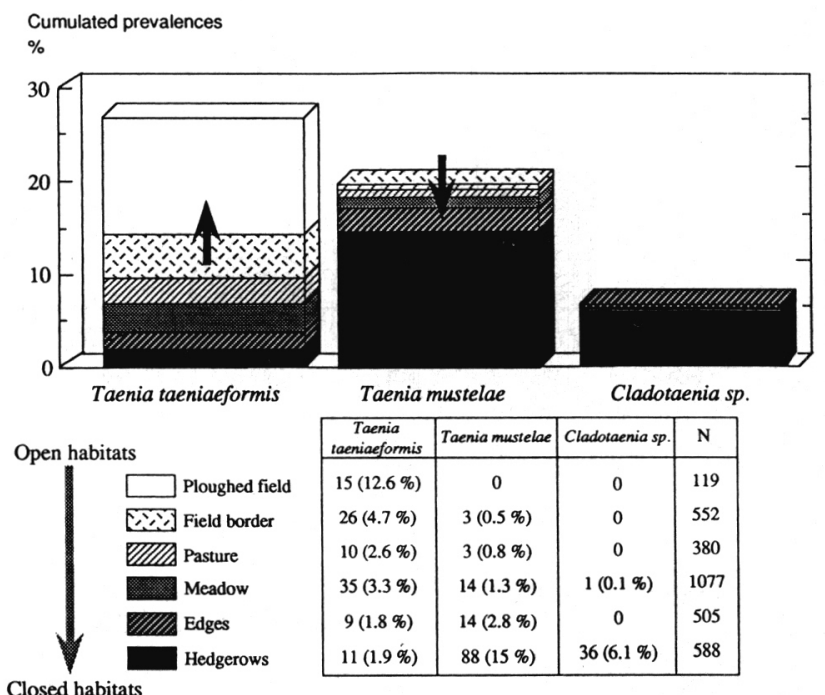

Closed habitats

FIG. 5. - Cumulated prevalences according to each species of cestodes and to habitats $(\mathrm{N}=$ total number of rodents; columns indicates the number of infested rodents and, between parentheses, the prevalences).

ders of close habitats $2.8 \%(1 / 36)$, and in meadows $2.7 \%$ $(5 / 185)$. Thus, the open habitat/close habitat gradient of prevalence was confirmed $(p<0.008)$.

\section{Prevalence/Time Relationships}

Figure 6 shows the age pattern of the host population according to cestode species and seasons.

No rodents born after the winter seemed to be infested with $T$. taeniaeformis before October (Fig. 6a). The minimum duration of larval development given by Hutchinson (1958) was about one month. The weights of crystalline lens of the two youngest infested $M$. arvalis in October was 3,8 and $3,2 \mathrm{mg}$. The age of both rodents did not exceed one month. Thus the infestation season seemed to be from September to March. P. subterraneus showed the same distribution. The only infestations in $M$. agrestis were observed in April in old animals. These results are consistent with those on $M$. arvalis and $P$. subterraneus. Parasite prevalence in rodents having survived the winter (crystalline lens weight $>3,5 \mathrm{mg}$ ) and which were captured in April, was higher than that of the same cohort captured in summer and autumn (9.9 and $4 \%$, respectively; $p<0.05)$ : the survival of $M$. arvalis infested with $T$. taeniaeformis seemed to be low compared to that recorded for E. multilocularis, and for which reverse proportions have been reported (Delattre et al., 1988). P. subterraneus showed the same trends even though the numbers were too low to be statistically significant.

Infestation with Cladotaenia sp. (Fig. 6b) only studied for the Bank Vole (C. glareolus) showed the same temporal distribution pattern as $T$. taeniaeformis. Laboratory studies of Freeman (1959) recorded that the development of a visible cyst takes two or three weeks. This result and the fact that the firt cases of infestation were recorded in August show that the infestation season extends from July to March. The results obtained from a small number of infested $M$. arvalis and Apodemus sp. are in keeping with this conclusion. On the other hand, the temporal distribution of infested $C$. glareolus showed great inter-annual variations of prevalence: 27 of the 32 infested rodents were captured in 1985 ( $p<0.05)$.

Unlike the other species, the prevalence of $T$. mustelae seemed to be more regular throughout the year, at least in C. glareolus and in M. arvalis (Fig. 6c). The minimal age at which the parasite could be detected was very low (age of rodents less than one month). This would be expected if there was a very rapid development of the cyst.

\section{DISCUSSION}

Delattre et al. $(1988,1990)$ showed large variations in the prevalence of $E$. multilocularis, with the best habitat for infection being the borders of ploughed fields or other areas where below ground survival of $E$. multilocularis eggs is possible. The spatial distribution of the prevalence of $T$. taeniaeformis was similar to that of E. multilocularis. In contrast $T$. mustelae showed a reverse gradient. Freeman (1959) and Leiby and Dyer (1971) reported that receptivity to cestodes varied according to rodent species and even rodent strains. Most rodents species did not occupy all the habitats of the study area. For example, C. glareolus is almost absent in the grasslands and $M$. arvalis was very seldom observed in the hedges of the bocage. In these cases, it was impossible to separate variations in the prevalence related to interspecific differences of sensitivity from those related to the distribution of rodent species in different habitats. Accepting the existence of both hypotheses, we pooled the results of each rodent species. Based on these pools, gradients of prevalence between open habitats and close habitats appeared in all the cases.

The prevalence of cestodes varied according to time at the inter annual level with $T$. mustelae at least. At the seasonal level, all species of cestodes showed interseasonal variations of prevalence. The summer phase of the cycle was critical for E. multilocularis (Delattre et al., 1988), T. taeniaeformis and Cladotaenia sp. It was difficult to interprete results for $T$. mustelae, although it may be assumed that there are specific periods of infestation.

We are aware these results integrate the result of the action of numerous factors that we cannot separate. Biogeographical and mesoclimatological factors being involved on this scale, factors that determine the transmission dynamics of each host-parasite system include the following:

1) microclimatological conditions supporting egg-survival probably represent the most critical point of the cycle. This 


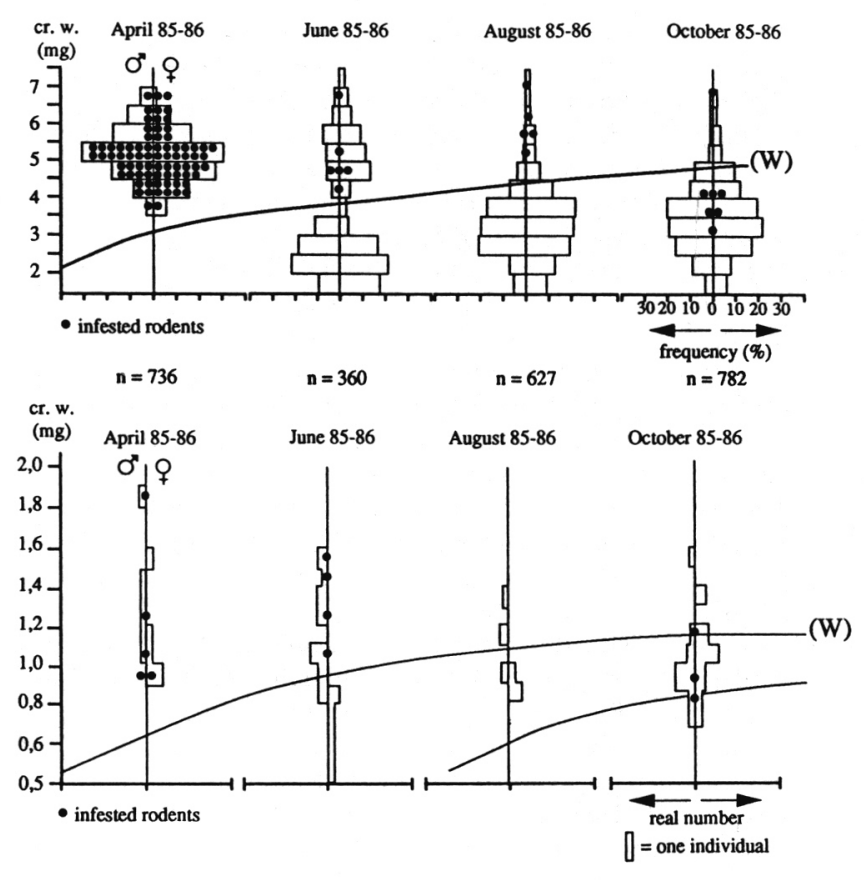

$a$

FIG. 6. - Distribution of infested rodents within the age pattern of their population according to seasons. Overlapped curves show example of increasing crystalline lens weight according to age: rodents born before winter are above the curve " $\mathrm{W}$ ", those born after the winter are under the curve.

a) Taenia taeniaeformis: top = Microtus arvalis, bottom = Pitymys subterraneus $-b$ ) larva of Cladotaenia sp. and Clethrionomys glareolus - c) Taenia mustelae: top = Microtus arvalis, bottom = Clethrionomys glareolus.

can be modified by man on a limited (= local) scale (e. $g$. ploughed fields for E. multilocularis and T. taeniaeformis);

2) defecation behaviour and movements of definitive hosts can also be important. The high prevalence of $\mathrm{Cla}$ dotaenia sp. under a tree and a hedge can be related to their use by birds of prey as a roost. The same kind of relationship can be established between the foraging strategies of predators and the aggregated distribution of parasites. Further observations were noted to support this:

$-T$. taeniaeformis: differences in prevalence were recorded inside the bocage. Predators seemed to concentrate their hunting effort within specifis areas over about 1 ha although we were unable to separate these areas from unfrequented ones according to landscape criteria (Herrenschmidt, 1984; Giraudoux, 1991),

- the high prevalence of $T$. mustelae in close habitats can be related to the preference of Mustelidae for this kind of habitats;

3) the longevity of the tapeworm in definitive hosts may be a critical factor determining the parasite survival within
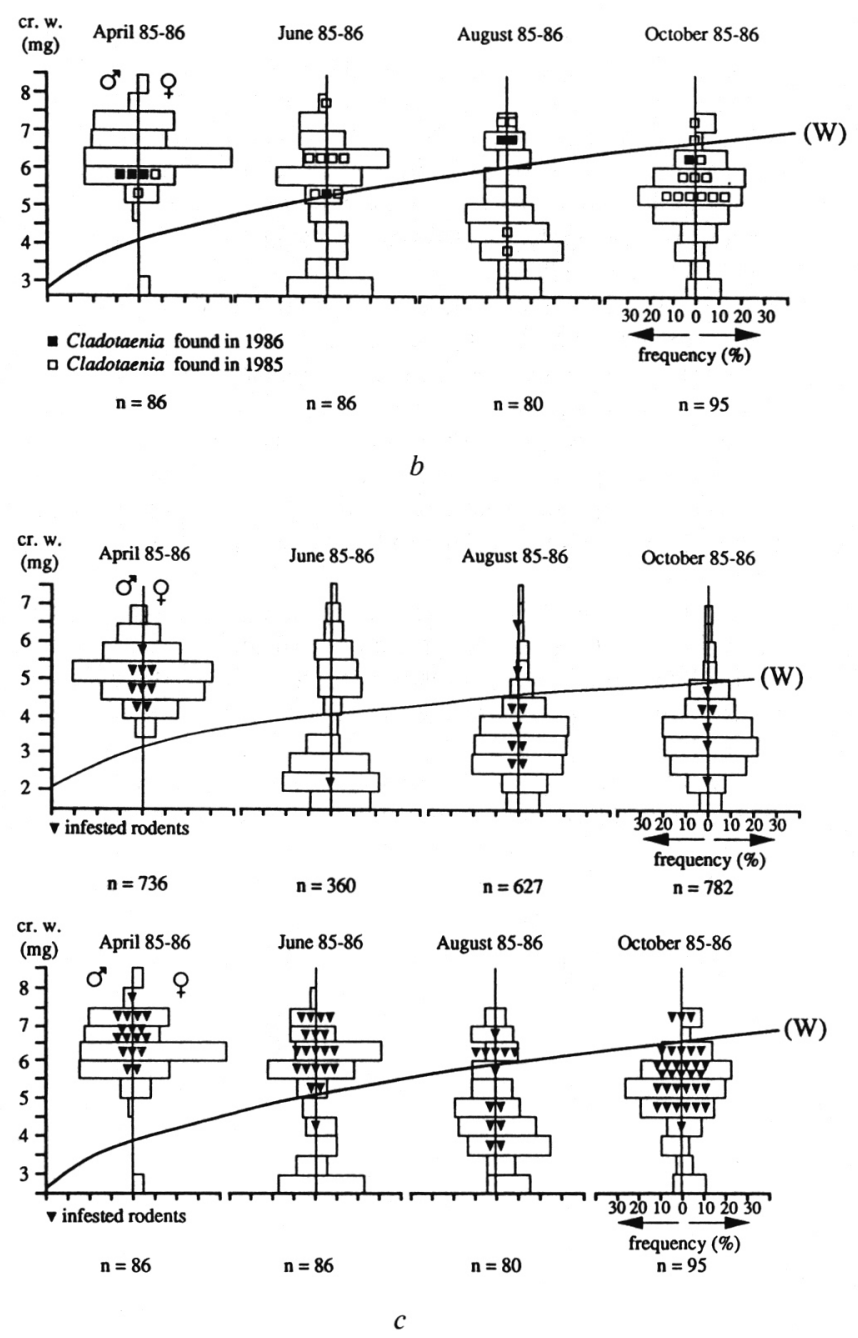

unfavorable seasonal conditions of egg-survival (e. g. in late spring and summer);

4) spatial distribution and density of rodents can determine the level of transmission;

5) genetic structure of host and parasite populations can be more or less favourable for transmission.

Acknowledgments. - We are indebted to Mr. Ashrord (Faculté de Médecine, Montpellier), J. BAudRY (Institut National de la Recherche Agronomique, Saint-Pierre/Dives), M. A. Gemmel (Dept. of Clinical Veterinary Medicine of the Cambridge University), L. GRÜNER (Institut National de la Recherche Agronomique, Nouzilly), for reviewing the manuscript. Ms. ReRAT (Institut National de la Recherche Agronomique, Jouy-en-Josas) helped us to translate it in English. A financial support has been provided by the Écologie et Gestion du Patrimoine Naturel Committee (Ministère de l'Environnement - contrat d'étude "Écologie du Paysage »).

\section{REFERENCES}

Bourlière F., Spitz F. : Les critères d'âge chez les mammifères. In: Problèmes d'écologie, la démographie des populations de vertébrés. Masson, Paris, 1975, 57-75. 
Dedet J. J. : Rôle de la cartographie en épidémiologie. Principes généraux. Modalités d'application. Méd. Mal. Infect., 1977, 7, 178-186.

Delattre P., Giraudoux P., Quéré J. P. : Conséquences épidémiologiques de la réceptivité d'un nouvel hôte intermédiaire du Taenia multiloculaire (Echinococcus multilocularis) et de la localisation spatiotemporelle des rongeurs infestés. C. R. Acad. Sci., 1990, 310 (III), 339-344.

Delattre P., Pascal M., Damange J. P. : Vers une stratégie d'étude épidémiologique de l'Échinococcose alvéolaire. À propos de cas d'infestation observés chez Microtus arvalis P. dans le Doubs (France). Ann. Parasitol. Hum. Comp., 1985, 60, 389-405.

Delattre P., Pascal M., Le Pesteur M. H., Giraudoux P., Damange J. P. : Caractéristiques écologiques et épidémiologiques de l'Echinococcus multilocularis au cours d'un cycle complet des populations d'un hôte intermédiaire (Microtus arvalis). Can. J. Zool., $1988,66,2740-2750$.

Freeman R. S. : On the taxonomy of the genus Cladotaenia, the life history of $C$. globifera (Batsch, 1786) and C. circi (Yamaguti, 1935), and a note on distinguishing between the plerocercoids of the genera Paruterina and Cladotaenia. Can. J. Zool., 1959, 37, 317-340.

Giraudoux P. : Utilisation de l'espace par les hôtes du Ténia multiloculaire, Echinococcus multilocularis : conséquences épidémiologiques. Thèse doct., Dijon, 1991, $109 \mathrm{p}$.

Goulty G. A. : A dictionary of landscape. Avebury Technical, Aldershot, 1991, 309 p.
Herrenschmidt V. : Aspects de la dynamique spatio-temporelle des relations prédateurs-proies en milieu forestier. Thèse de $3^{\mathrm{e}}$ cycle, Université Pierre-et-Marie-Curie, Paris, 1984, 89 p.

Hutchinson W. M. : Studies of Hydatigera taeniaeformis. I. Growth of the larval stage. J. Parasitol., 1958, 44, 574-582.

Legay J. M., Debouzie D. : Introduction à une biologie des populations. Masson, Paris, 1985, $149 \mathrm{p}$.

Le Louarn H. : Détermination de l'âge par la pesée des cristallins chez quelques espèces de rongeurs. Mammalia, 1971, 35, 636-643.

Leiby P. D., Dyer W. G. : Cyclophyllidean tape worms of wild carnivora. In: Parasitic disease of wild mammals, Davis J. W. and Anderson R. C. Iowa State University Press, 1971, 366 p.

Le Pesteur M. H. : Analyse comparative des cycles parasitaires de cinq cestodoses larvaires de rongeurs. Etude in natura en Franche-Comté (France). Thèse vét., Nantes, 1990, 129 p.

Martinet L. : Détermination de l'âge chez le Campagnol des champs (Microtus arvalis) par la pesée du cristallin. Mammalia, 1966, 30, 425-430.

Rioux J. A., Lanotte G., Cousserans J., Gabinaud A., Corre J. J. : Écologie, développement et santé publique. Bases écologiques de l'analyse d'un système épidémiologique; foyers d'infection et parasitocœnose; stratégies d'enquête et d'intervention. In: Écologie et développement des ressources de l'espace. C. N. R. S., 1981, 1 vol., 468 p.

Spitz F., Le Louarn H., Poulet A., Dassonville B. : Standardisation des piégeages en ligne pour quelques espèces de rongeurs. Rev. Écol. Terre et Vie, 1974, 24, 564-578.

Des microfiches et des microfilms de cette publication peuvent être obtenus auprès de :

This publication is available in microform from:

MASSON-SPPIF (réf. MIMC), 120, boulevard Saint-Germain, F-75280 Paris Cedex 06.

(c) Masson, Paris, 1992

Le Directeur de la Publication : D J. TALAmon

Tous droits de traduction, d'adaptation et de reproduction par tous procédés réservés pour tous pays.

Toute reproduction ou représentation intégrale ou partielle, par quelque procédé que ce soit, des pages publiées dans le présent ouvrage, faite sans l'autorisation de l'éditeur est illicite et constitue une contrefaçon. Seules sont autorisées, d'une part, les reproductions strictement réservées à l'usage du copiste et non destinées à une utilisation collective, et d'autre part, les courtes citations justifiées par le caractère scientifique ou d'information de l'œuvre dans laquelle elles sont incorporées (art. L. 122-4, L. 122-5 et L. 335-2 du Code de la propriété intellectuelle).

Des photocopies payantes peuvent être réalisées avec l'accord de l'éditeur. S'adresser au : Centre français d'exploitation du droit de copie, 3, rue Hautefeuille, 75006 Paris. Tél. 43-26-95-35.

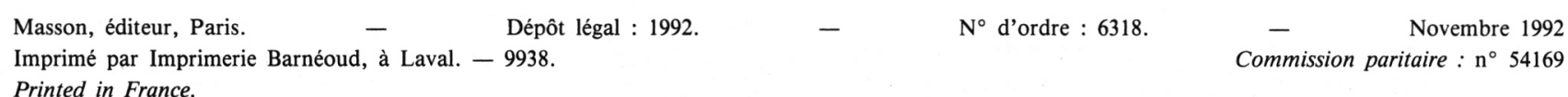

Printed in France. 